\title{
TRAIL receptor mediates inflammatory cytokine release in an NF-кB-dependent manner
}

\author{
Wanhu Tang ${ }^{1}$, Weimin Wang ${ }^{1}$, Yaxi Zhang ${ }^{1}$, Shilian Liu ${ }^{1}$, Yanxin Liu ${ }^{1}$, Dexian Zheng ${ }^{1}$ \\ ${ }^{I}$ National Laboratory of Medical Molecular Biology, Institute of Basic Medical Sciences, Chinese Academy of Medical Sciences \& \\ Peking Union Medical College, 5 Dong Dan San Tiao, Beijing 100005, China
}

In the present article, we report that DR4 or DR5 overexpression dramatically activates the release of the inflam-

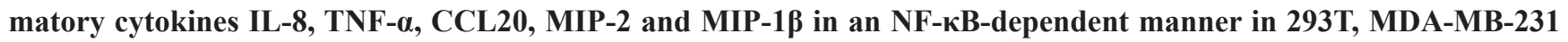
and HCT-116 cells. We showed that death receptor-mediated signals were extracellular domain-independent, whereas the effect of overexpression of the DR4 intracellular domain was much less potent. The TRADD-TRAF2-NIKIKK $\alpha / \beta$ signaling cascade, which plays an essential role in TNF-induced NF- $\kappa$ B activation, was found to be involved in tumor necrosis factor-related apoptosis-inducing ligand (TRAIL) receptor-mediated signal transduction. The FADD-caspase signaling pathway, which has been reported to be mostly related to apoptosis, was identified as being essential for DR4 or DR5 overexpression-mediated NF-кB activation and cytokine secretion and crosstalks with the TRADD-TRAF2-NIK-IKK $\alpha / \beta$ signaling cascade. Furthermore, a DR5 agonistic antibody (AD5-10) triggered the inflammatory cytokine release. These data, together with previous reports, provide strong evidence that TRAIL and TRAIL receptors play an important role in inflammation.

Keywords: TRAIL receptor, inflammation, cytokine, NF- $\mathrm{B}$

Cell Research (2009) 19:758-767. doi: 10.1038/cr.2009.57; published online 12 May 2009

\section{Introduction}

Tumor necrosis factor-related apoptosis-inducing ligand (TRAIL) is known to induce apoptosis in a variety of tumor cells and virally infected cells, but not in most normal cells $[1,2]$. Recombinant soluble TRAIL and TRAIL receptor-specific agonistic antibodies have attracted considerable attention for their potential utility in cancer therapy. To date, five TRAIL receptors have been identified in humans. Among these receptors, DR4 and DR5 possess an intracellular tail containing the death domain, which mediates cell death via apoptosis [3-5]. TRAIL receptor overexpression as well as TRAIL treatment induced apoptosis in different cell lines. Once

Correspondence: Dexian Zheng or Yanxin Liu Tel: +8610 6529 6409; Fax: +8610 65105102 E-mail: zhengdx@tom.com

Abbreviations: TRAIL (tumor necrosis factor-related apoptosis-inducing ligand); DR (death receptor); DcR (decoy receptor); DISC (death-inducing signaling complex); DN (dominant negative)

Received 21 October 2008; revised 17 November 2008; accepted 17 December 2008; published online 12 May 2009 engaged, TRAIL receptors recruit a number of adaptor proteins, after which a signaling cascade is activated. The components of the death-inducing signaling complex (DISC) recruited by the TRAIL receptor have not been well defined. For example, there are controversial reports on the involvement of TRADD and RIP [5-8].

Most investigations about TRAIL have focused on its ability to induce apoptosis in cancer cells; however, the physiological functions of TRAIL and TRAIL receptors are much less well understood [9]. Both TRAILand TRAIL receptor-deficient animals display increased susceptibility to tumor metastasis $[10,11]$. It has been reported that TRAIL deficiency leads to autoimmune disease progression, as well as to defects in thymocyte negative selection, although the latter finding is controversial $[12,13]$. In addition, a role for TRAIL in the regulation of $\mathrm{CD}^{+} \mathrm{T}$ cell activation and memory has been demonstrated [14]. Previous reports demonstrated that TRAIL was also shown to be involved in the homeostatic control of endothelial biology; this finding illustrated the complex roles of TRAIL and the TRAIL receptor in inflammation, although many of the reports are controversial [15-18]. It has also been shown that TRAIL can induce 
IL-8 and MCP-1 expression in various cell lines [19-21], but the precise role of TRAIL in inflammation remains to be clarified. In the present study, DR4 or DR5 was overexpressed in 293T, MDA-MB-231 and HCT-116 cell lines, and the expression levels of inflammatory cytokines were then determined. Our results demonstrate that DR4 or DR5 overexpression, as well as DR5 engagement activated the release of a number of inflammatory cytokines in an NF- $\kappa \mathrm{B}$-dependent manner.

\section{Results}

Overexpression of DR4 or DR5 activates inflammatory cytokine release

$293 \mathrm{~T}$ cells were transfected with individual expression plasmids of the two TRAIL receptors, and RTPCR was performed. As shown in Figure 1A, among the cytokines we investigated, mRNA expression levels of IL-8, TNF- $\alpha$, CCL20, MIP-2 and MIP-1 $\beta$ were dramatically induced. To determine whether this result was 293T-specific, lentiviral vectors for DR4 and DR5 were transduced into MDA-MB-231 and HCT-116 cells. As expected, death receptor overexpression upregulated the mRNA production of IL-8, CCL20 and MIP-2 in these two cell lines (Figure 1B). Based on their high transfection efficiency, 293T cells were selected for the subsequent studies. As shown in Figure 1C, secretion of IL8 , TNF- $\alpha$ and CCL20 was also increased in the medium of 293 T cells, as determined by cytokine measurement. Collectively, these results indicate that overexpression of DR4 or DR5 in 293T cells activated inflammatory cytokine release.

DR4- and DR5-mediated inflammatory cytokine release is $N F-\kappa B$-dependent

To investigate whether NF- $\kappa \mathrm{B}$ was involved in DR4and DR5-mediated inflammatory cytokine release, 293T cells were transfected with a plasmid expressing an $I_{\kappa} B$ dominant negative form $\left(\mathrm{I}_{\kappa} \mathrm{B} \mathrm{DN}\right)$ and $\mathrm{NF}-\kappa \mathrm{B}$ activation was determined by luciferase assay. As shown in Figure $2 \mathrm{~A}$, transfection of the $\mathrm{I}_{\kappa} \mathrm{B}$ DN plasmid in cells with DR4 or DR5 overexpression significantly attenuated $\mathrm{NF}-\kappa \mathrm{B}$ activity; IKK inhibitor II (Wedelolactone) could also block death receptor-mediated NF- $\kappa \mathrm{B}$ activation, although it was not as efficient as the $\mathrm{I}_{\kappa} \mathrm{B} \mathrm{DN}$ construct. Meanwhile, RT-PCR (Figure 2B), luciferase assay (Figure $2 \mathrm{C}$ ) and cytokine measurement (Figure 2D) revealed that upregulation of IL-8, TNF- $\alpha$, CCL20, MIP-2 and MIP$1 \beta$ was significantly blocked by $\mathrm{I}_{\kappa} \mathrm{B}$ DN and IKK inhibitor II, indicating that DR4- and DR5-mediated inflammatory cytokine release was NF- $\mathrm{BB}$-dependent.

DR4- and DR5-mediated inflammatory cytokine release and apoptosis are not dependent on their extracellular domain

To investigate which domain of the death receptors
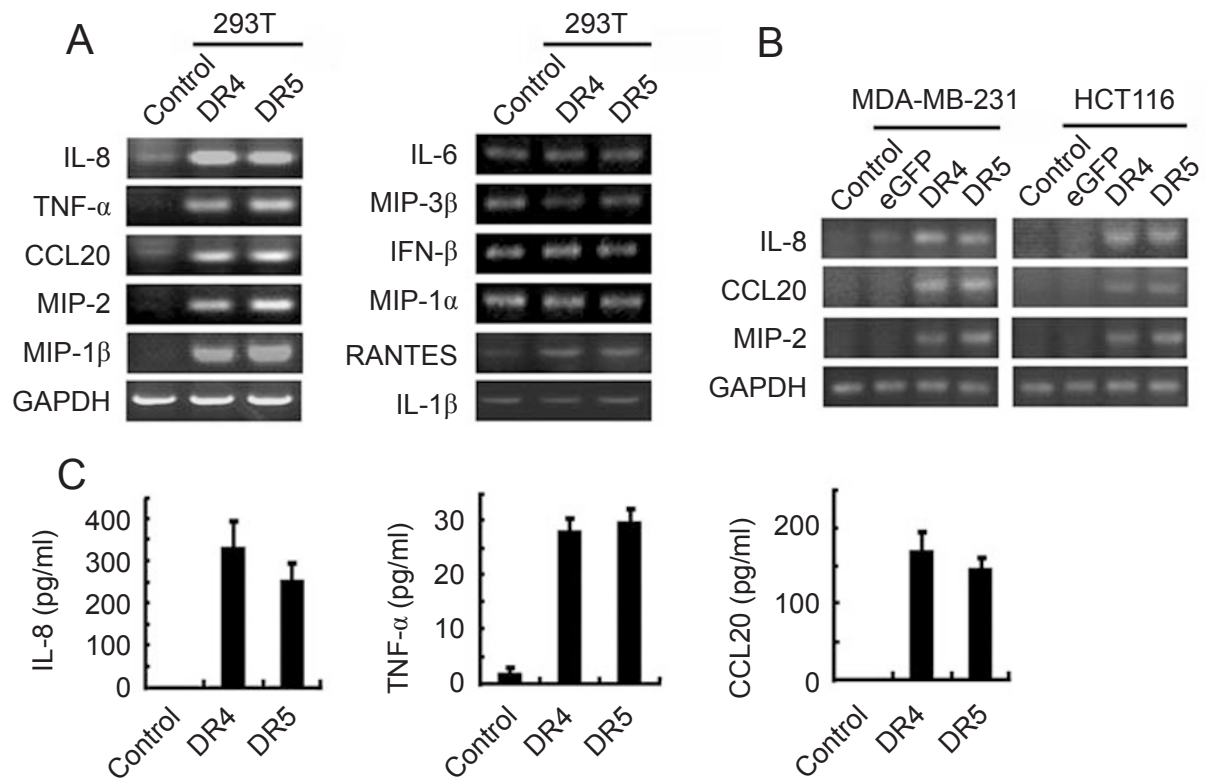

Figure 1 DR4 and DR5 overexpression activated inflammatory cytokine release. (A) 293T cells were transfected as indicated. Total RNA was isolated for RT-PCR. pCMV-Flag empty vectors were used as a control. (B) The MDA-MB-231 and HCT116 cells were transduced with lentiviral vectors as indicated, and RT-PCR was performed. (C) Similar to (A), except that the cell culture supernatants were collected for cytokine measurement. 

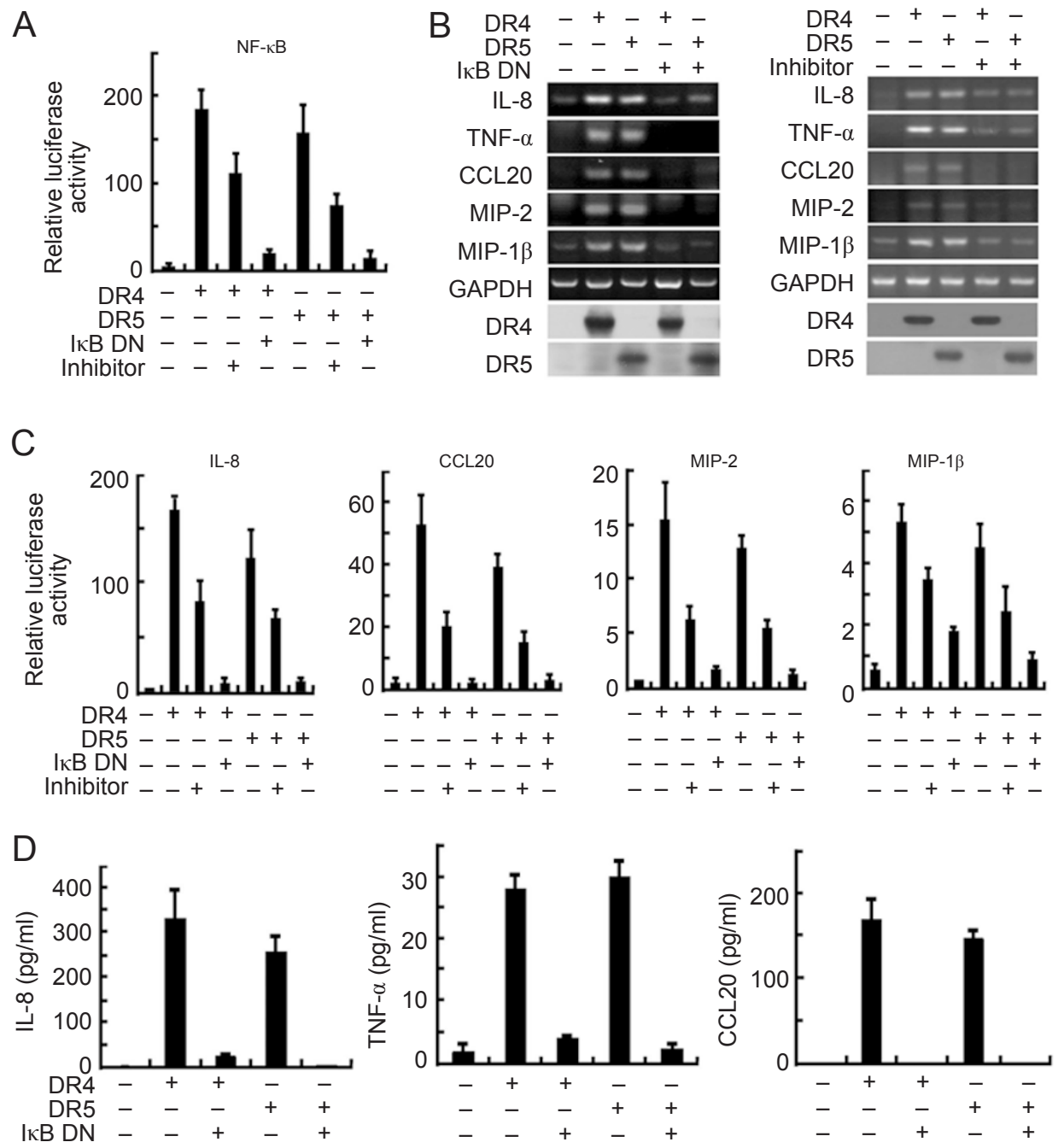

Figure 2 DR4 and DR5 overexpression-activated inflammatory cytokine release was NF-kB-dependent. (A and B) 293T cells were transfected with corresponding plasmids and IKB DN, or pretreated with IKK inhibitor II (Wedelolactone) as indicated. Subsequently, luciferase activity assay and RT-PCR were performed, respectively. The expression levels of DR4 and DR5 were confirmed by Western blot assay. pCMV-Flag empty vectors were used as a control. (C) Similar to (A), except that different reporter constructs were used. (D) Similar to (B), except that cytokine measurements were performed.

plays an essential role in DR4 or DR5 overexpressionmediated NF- $\kappa \mathrm{B}$ activation and apoptosis, plasmids expressing various defective TRAIL receptors were engineered as depicted in Figure 3A and transfected into $293 \mathrm{~T}$ cells. Expression levels of the various TRAIL receptors were confirmed by western blot (Figure 3B). $\mathrm{NF}-\kappa \mathrm{B}$ activation was evaluated using luciferase activity assay. Cell death was observed under a light microscope. As shown in Figure 3C, constructs encoding the cytoplasmic domain of DR4 (DR4 CD) and decoy receptor (DcR) 2 were less potent in stimulating NF- $\kappa \mathrm{B}$ activation, whereas DR5 CD, DR4 STMCD and DR5 STMCD activated $\mathrm{NF}_{-} \mathrm{\kappa B}$ to a level similar to that of the corresponding wild-type constructs. Moreover, overexpression of these constructs, except for DR4 CD and DcR2, markedly triggered apoptosis in $293 \mathrm{~T}$ cells (Figure 3D). These results indicate that the lack of extracellular domains did not affect the ability of DR4 and DR5 to activate NF- $\mathrm{B}$ dependent inflammatory cytokine release or apoptosis.

The TRADD-TRAF2-NIK-IKK $\alpha / \beta$ signaling cascade is involved in DR4 and DR5 overexpression-mediated NF$\kappa B$-dependent inflammatory cytokine release

To investigate the signaling pathway stimulated by DR4 or DR5 overexpression, a TRADD dominant negative construct (TRADD DN) was transfected into 293T cells with or without DR4 or DR5 overexpression. NF$\kappa \mathrm{B}$ activation was evaluated by a luciferase activity as- 


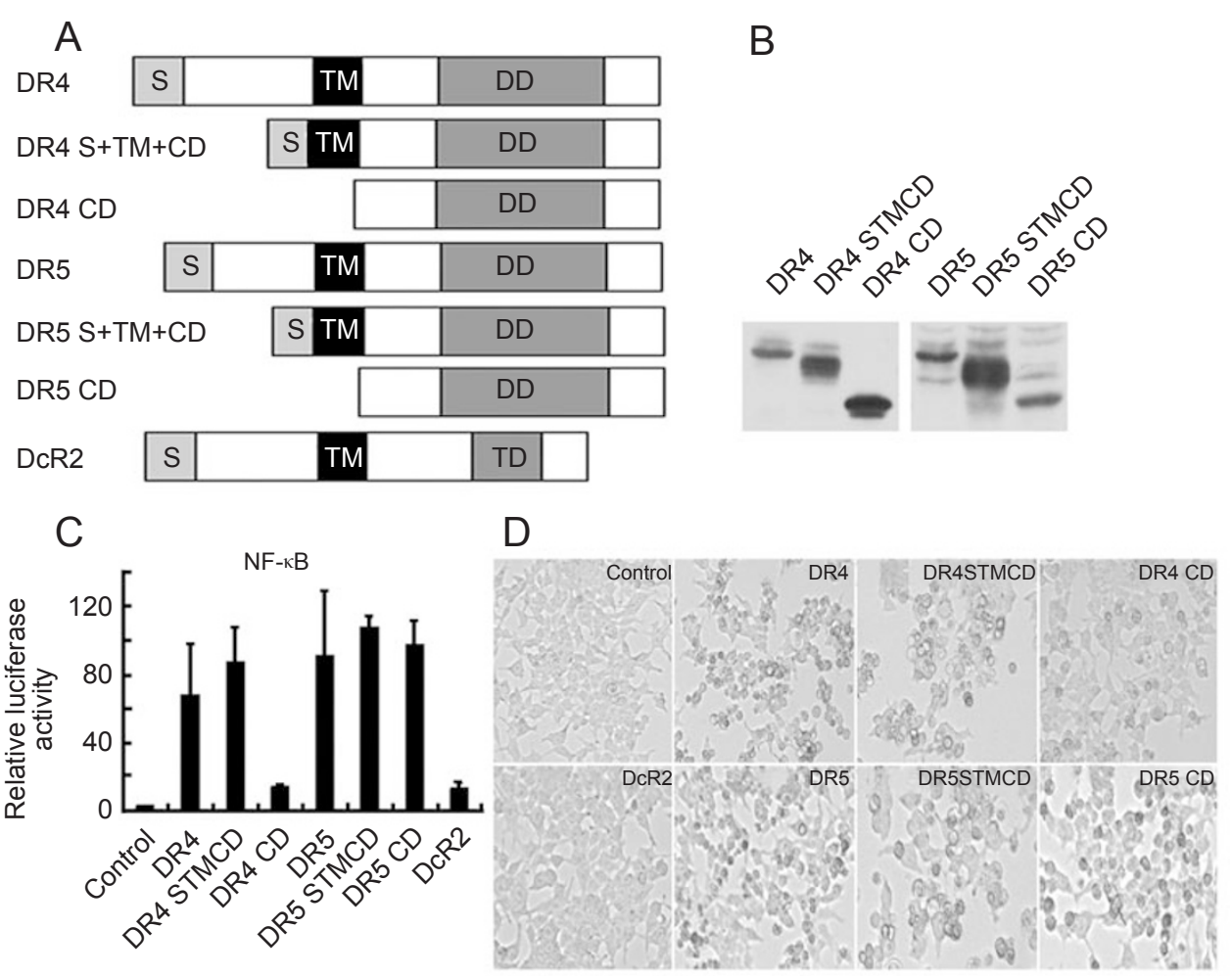

Figure 3 DR4 and DR5 overexpression-mediated NF-кB activation and apoptosis were not dependent on their extracellular domains. (A) Various defective TRAIL receptor constructs were engineered as indicated and transfected into $293 \mathrm{~T}$ cells. Overexpression of the various receptors was confirmed by Western blot assay. (B) NF-kB activation was evaluated via a luciferase activity assay. (C) Cell death was observed under a light microscope. (D) The pCMV-Flag empty vectors were used as controls. S, signaling peptide; TM, transmembrane domain; DD, death domain; CD, cytoplasmic domain.

say, and cytokine release in the medium was determined by cytokine measurement. As shown in Figure 4A and 4B, TRADD DN transfection reduced TRAIL receptormediated NF- $\kappa \mathrm{B}$ activation and release of IL-8, TNF- $\alpha$ and CCL20. It is well known that the TRAF2-NIKIKK $\alpha / \beta$ signaling cascade acts downstream of TRADD. Therefore, the possible role of TRAF2-NIK-IKK $\alpha / \beta$ was further investigated using corresponding DN construct transfection. The luciferase activity assay showed that these DN constructs inhibited NF- $\mathrm{KB}$ activation significantly (Figure 4C). RT-PCR (Figure 4D) and cytokine measurement (Figure 4E) demonstrated that induction of inflammatory cytokines (IL-8, TNF $\alpha$ and CCL20) was inhibited by these DN constructs. These data indicate that the TRADD-TRAF2-NIK-IKK $\alpha / \beta$ signaling pathway was involved in TRAIL receptor overexpression-activated NF- $\mathrm{B}$-mediated inflammatory cytokine release.

DR4 or DR5 overexpression-activated inflammatory cytokine release involves the FADD-caspase signaling pathway

To further clarify the TRAIL receptor overexpression- mediated signaling pathway, FADD DN plasmid and a cytokine response modifier A (CrmA) expression construct were transfected into $293 \mathrm{~T}$ cells with or without DR4 or DR5 overexpression and then a luciferase reporter gene assay was performed. As shown in Figure 5A, these two constructs efficiently inhibited TRAIL receptor overexpression-mediated NF- $\kappa \mathrm{B}$ activation. Meanwhile, upregulation of the inflammatory cytokines IL-8, TNF- $\alpha$ and CCL20 was blocked by these two constructs at both the mRNA level, as determined by RT-PCR (Figure 5B), and the protein level, as determined by cytokine measurements (Figure 5C). Earlier investigations into the roles of FADD and caspases in NF- $\kappa \mathrm{B}$ activation are controversial, and studies in MCF-7 cells were not consistent with our conclusions [5]. To present further evidence for our results, we examined the ability of FADD and caspase- 8 to activate NF- $\mathrm{KB}$ by transfection of FADD or caspase- 8 expression plasmids. As shown in Figure 5D, overexpression of FADD or caspase- 8 activated NF- $\mathrm{B}$, which could be inhibited by expression of a plasmid for CrmA or DN plasmids of NIK, IKK $\alpha$ and IKK $\beta$. Taking together these findings, we could conclude that the FADD- 

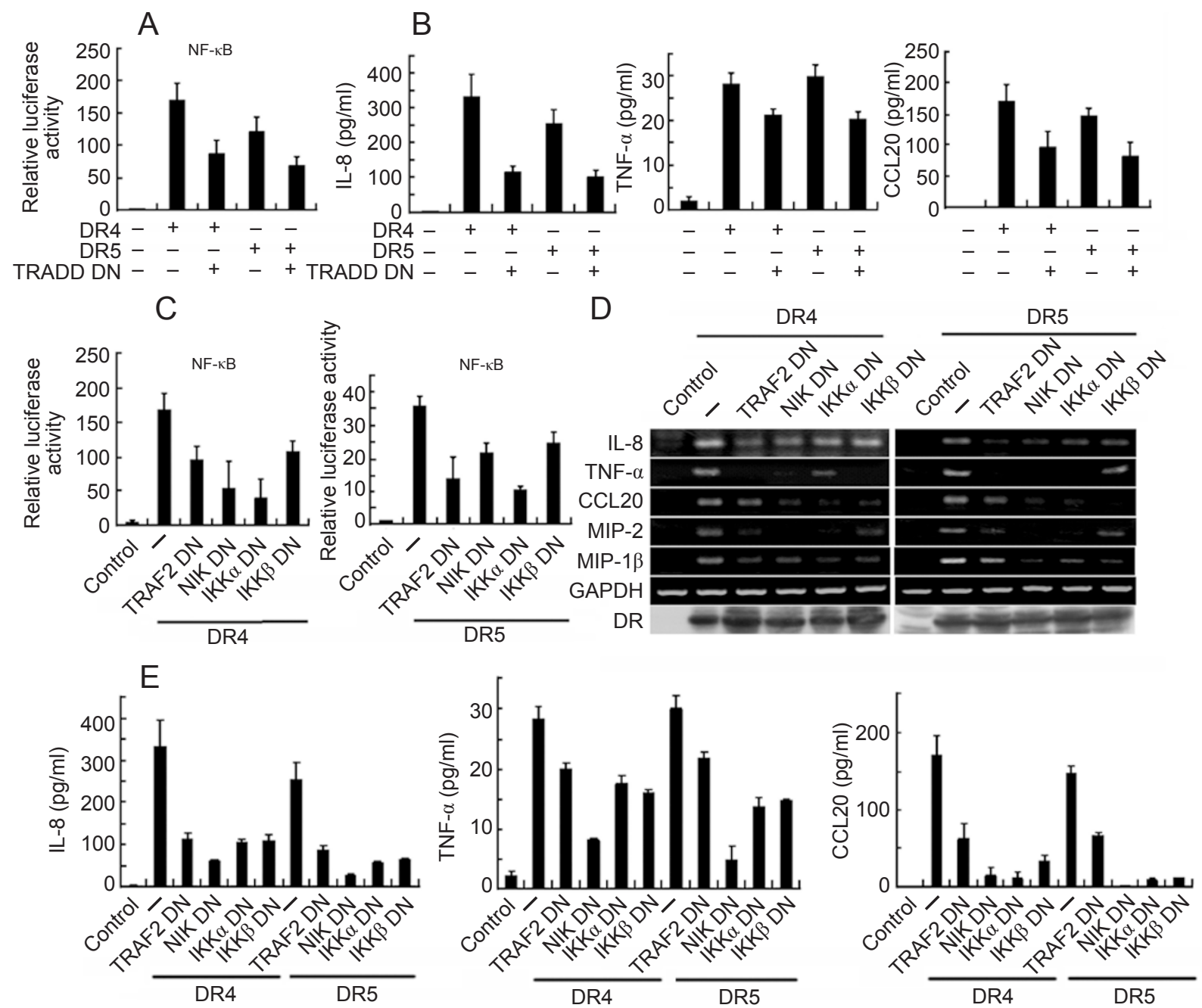

Figure 4 The TRADD-TRAF2-NIK-IKKa/ $\beta$ signaling pathway is involved in TRAIL receptor overexpression-mediated NF- $\kappa B-$ dependent inflammatory cytokine release. (A and B) 293T cells were transfected with TRADD DN and the corresponding plasmids as indicated, followed by luciferase activity assay and cytokine measurement. (C-E) 293T cells were transfected with TRAF2, NIK, IKKa/ $\beta$ DN and the corresponding plasmids as indicated, followed by luciferase activity assay, RT-PCR and cytokine measurement. Expression levels of DR4 and DR5 were confirmed by Western blot assay. pCMV-Flag empty vectors were used as controls.

caspase signaling pathway, which has been reported to be mostly related to apoptosis, is essential for death receptor overexpression-mediated inflammatory cytokine release, and may crosstalk with the TRADD-TRAF2-NIK-IKK $\alpha / \beta$ signaling cascade.

DR5 engagement by an agonistic antibody activates inflammatory cytokine release in a dose-dependent manner

Finally, we investigated whether death receptor engagement triggers inflammatory cytokine expression in 293T cells. The cells were treated with a novel agonistic anti-human DR5 monoclonal antibody (AD5-10) that was developed in our lab [22], followed by a luciferase assay for $\mathrm{NF}-\kappa \mathrm{B}$ activation. As shown in Figure $6 \mathrm{~A}$, AD5-10 treatment significantly activated NF- $\kappa \mathrm{B}$ in a dose-dependent manner. RT-PCR analysis revealed that AD5-10 could trigger inflammatory cytokine mRNA upregulation (Figure 6B). When cells were transfected with reporter plasmids for IL-8, CCL20, MIP-2 and MIP-1 $\beta$ followed by AD5-10 antibody treatment, NF- $\kappa$ B was activated, and expression of these cytokines was thereby transcriptionally upregulated, as revealed by a luciferase activity assay (Figure 6C). It was also found that AD510 could induce IL- 8, CCL2 0 and TNF- $\alpha$ release, as determined by cytokine measurement (Figure 6D). DISC components were also examined following DR5 activa- 

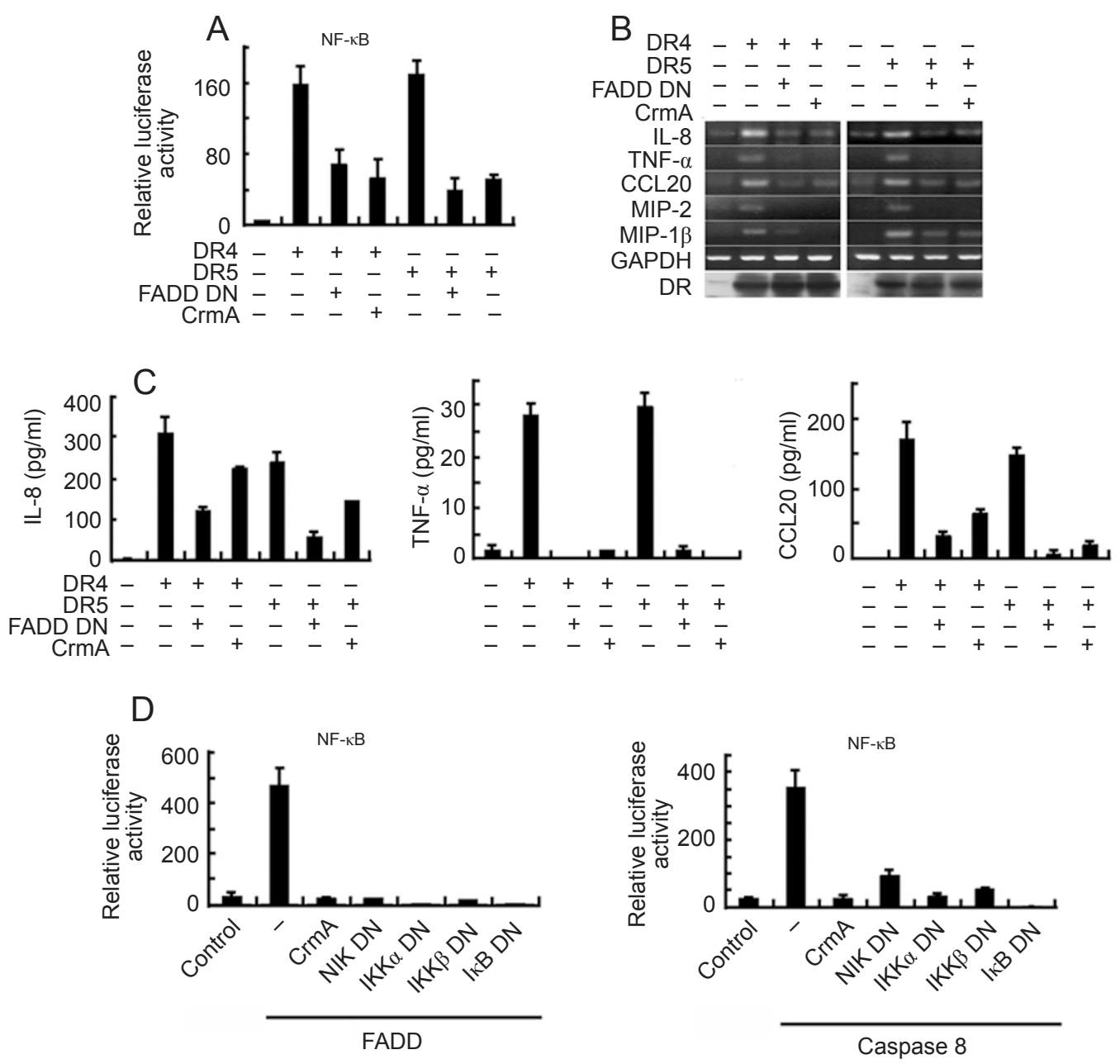

Figure 5 DR4 or DR5 overexpression activated inflammatory cytokine release through the FADD-caspase signaling pathway. (A-C) 293 T cells were transfected with FADD DN or CrmA and the corresponding constructs as indicated, followed by a luciferase activity assay, RT-PCR and cytokine measurement. Expression levels of DR4 and DR5 were determined by Western blot assay. (D) The cells were transfected with expression plasmids for FADD or caspase-8 and the corresponding constructs as indicated, followed by a luciferase activity assay. pCMV-Flag empty vectors were used as controls.

tion. The results showed that FADD, caspase- 8 and RIP were recruited into the DISC, whereas TRADD and TRAF2 were not detected (Figure 6E). Taken together, these findings indicate that DR5 ligation by its agonistic antibody also triggers inflammatory cytokine release in an NF- $\mathrm{BB}$-dependent manner.

\section{Discussion}

The direct function of TRAIL-activated NF- $\kappa \mathrm{B}$ remains unclear, although TRAIL has been reported to activate $\mathrm{NF}-\kappa \mathrm{B}$ in different cell lines. In the present study, we report for the first time that DR4 or DR5 overexpression, as well as DR5 engagement with its agonistic antibody activate the secretion of inflammatory cytokines, such as IL-8, CCL20, TNF- $\alpha$, MIP-2 and MIP-1 $\beta$, in an $\mathrm{NF}-\kappa \mathrm{B}-$ dependent manner. These results provide strong evidence that DR4 and DR5 are involved in inflammation in addition to apoptosis. To our knowledge, this is the first demonstration that TRAIL receptor overexpression activates inflammatory cytokine release. It is also the first report that indicates the involvement of TNF- $\alpha$, MIP-2 and MIP-1 $\beta$ in the TRAIL receptor-mediated signaling pathway.

Dominant negative constructs, which encode inactive products, have been widely used in the study of signaling pathways. Since they act antagonistically towards their wild-type counterparts, DN constructs exhibit high specificity. DN constructs have been proved to be effective, but there is one major drawback to this strategy; 
A

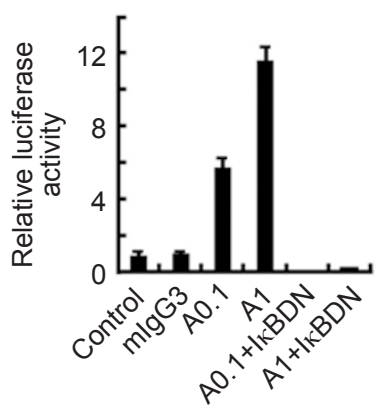

B

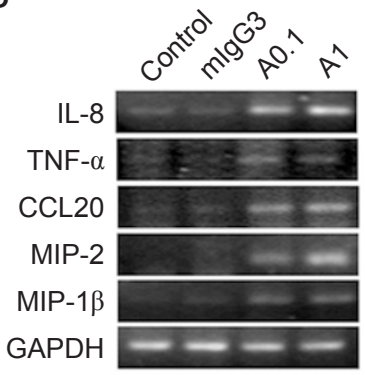

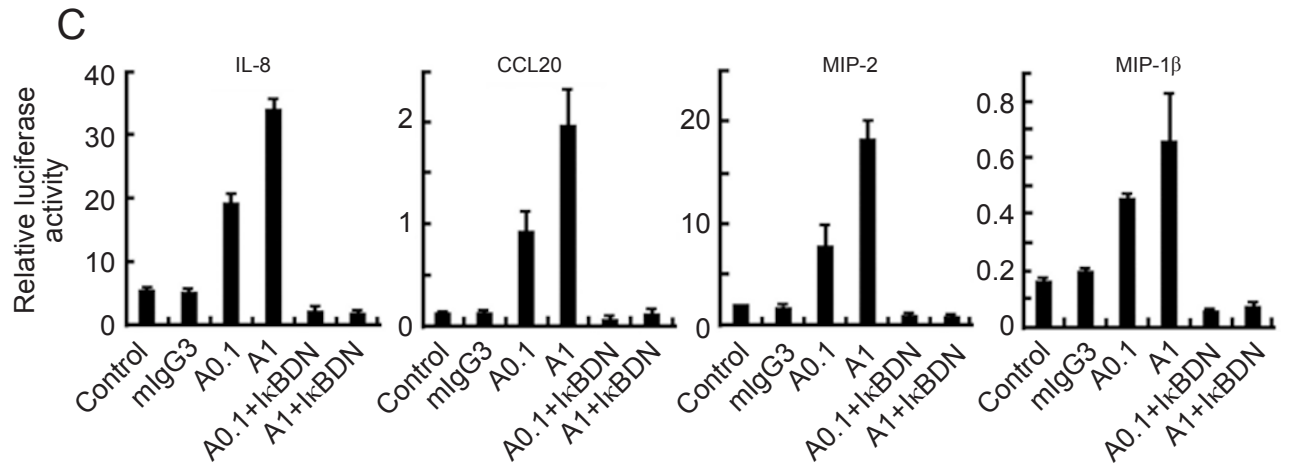

$\mathrm{D}$

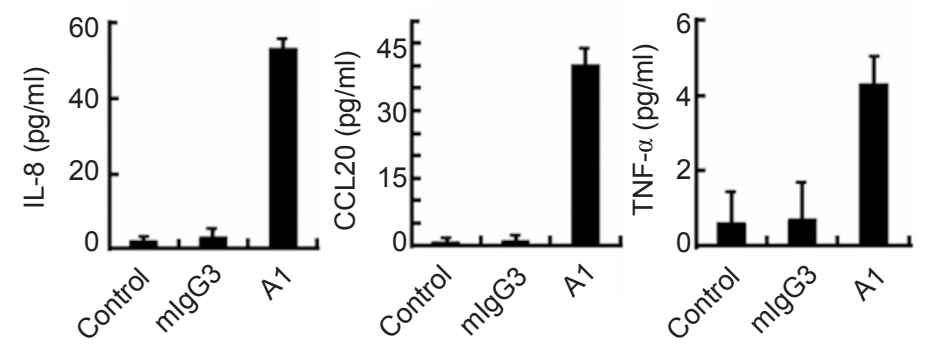

$E$

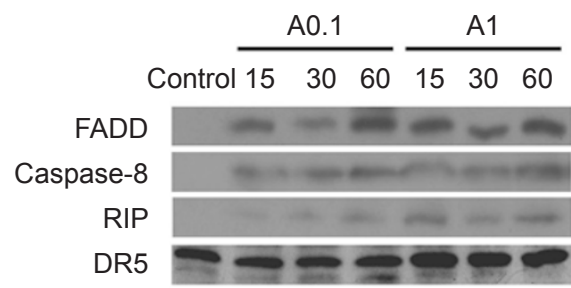

Figure 6 DR5 engagement by an agonistic antibody AD5-10 (IgG3) activated inflammatory cytokine release in 293T cells. Mouse IgG3 was used as an antibody isotype control. (A) 293T cells were transfected with NF- $\mathrm{B}$ luciferase reporter plasmids and incubated with $0.1 \mu \mathrm{g} / \mathrm{ml}$ or $1 \mu \mathrm{g} / \mathrm{ml} \mathrm{AD5-10,} \mathrm{followed} \mathrm{by} \mathrm{a} \mathrm{luciferase} \mathrm{activity} \mathrm{assay.} \mathrm{(B)} \mathrm{293T} \mathrm{cells} \mathrm{were} \mathrm{treated} \mathrm{with}$ AD5-10 at $0.1 \mu \mathrm{g} / \mathrm{ml}$ and $1 \mu \mathrm{g} / \mathrm{ml}$, followed by RT-PCR analysis. (C) Similar to (A), except that IL-8, CCL20, MIP-2 and MIP$1 \beta$ luciferase reporter plasmids were used as indicated. (D) The 293T cells were treated with AD5-10 at 0.1 $\mathrm{\mu g} / \mathrm{ml}$, followed by cytokine measurement. (E) 293T cells were treated with $0.1 \mu \mathrm{g} / \mathrm{ml}$ or $1 \mu \mathrm{g} / \mathrm{ml} \mathrm{AD5-10} \mathrm{for} \mathrm{a} \mathrm{time} \mathrm{course} \mathrm{as} \mathrm{indicated,} \mathrm{fol-}$ lowed by DISC analysis.

that is, transfection of the $\mathrm{DN}$ constructs leads to rapid accumulation of the mutant proteins, which may bind to proteins and localize to areas within the cell that are not physiologically relevant. As a solution to this potential drawback of DN constructs, we also used an IKK inhibitor to confirm the results obtained using $\mathrm{I}_{\kappa} \mathrm{B} \mathrm{DN}$.

Receptor oligomerization is considered necessary for signal transduction mediated by the death receptors [23]. 
We showed that TRAIL receptor overexpression, similar to treatment with TRAIL or a receptor-specific agonistic antibody, induced automatic oligomerization and triggered downstream signaling pathways; however, the death receptor extracellular domain was not required for triggering these signals.

Signaling studies demonstrated that the TRADDTRAF2-NIK-IKK $\alpha / \beta$ signaling cascade was involved in the death receptor overexpression-mediated signaling. It is reasonable to conclude that a high amount of receptor expression may amplify the interaction between receptors and adaptors, which leads to an amplification of signal transduction and consequent responses in the cells. It is possible that, upon TRAIL engagement, TRAIL receptors have a relatively weak ability to recruit adaptor proteins such as TRADD, whereas in the receptor overexpression system the ability could be significantly amplified and become detectable.

$\mathrm{NF}-\kappa \mathrm{B}$ was once regarded as the molecular determinant of TRAIL resistance that promoted the expression of survival factors, such as members of the IAP family (c-IAP1, c-IAP2 and XIAP) [24] and the Bcl-2 homologs

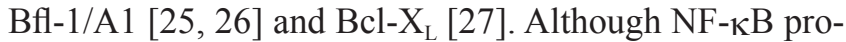
tects cells from apoptosis [28-30], TRAIL susceptibility does not correlate with constitutive $\mathrm{NF}-\kappa \mathrm{B}$ activation status in several cell lines $[31,32]$. We found that DR overexpression induced apoptosis concomitant with the activation of NF- $\kappa \mathrm{B}$, suggesting that TRAIL receptormediated apoptosis and NF- $\mathrm{KB}$ activation bifurcate downstream of caspases.

FADD and caspases play an essential role in the death signal transduction mediated by the death receptors $[6,8]$. We showed that blockade of the FADD-caspase signaling cascade inhibited death receptor-mediated NF- $\mathrm{kB}$ activation, suggesting that FADD and caspases may protect some cells from apoptosis. This is consistent with the reports by Chaudhary et al. [5, 21], whereas most earlier studies indicated that caspase activation blocked NF- $\mathrm{B}$ activation. This discrepancy might be a result of the different cell lines studied.

We found that DR5 engagement also induced NF$\kappa \mathrm{B}$ activation and inflammatory cytokine release. DR5 agonistic antibody treatment did not trigger apoptosis in TRAIL-resistant 293T cells, although caspase- 8 was recruited into the DISC. The fact that cleavage of caspase- 8 followed by cell death did not occur may be due to the expression of intracellular inhibitors. We showed that FADD-caspases were involved in TRAIL receptor overexpression-triggered $\mathrm{NF}_{-} \kappa \mathrm{B}$ activation, while AD510 treatment induced $\mathrm{NF}-\kappa \mathrm{B}$ activation without cell death. Our results demonstrated that TRAIL receptormediated NF- $\mathrm{NB}$ activation and inflammatory cytokine release occur via both caspase-dependent and -independent pathways.

Compared with death receptor overexpression, DR5 engagement was much less potent in triggering inflammatory cytokine release. Since DR5 agonistic antibody treatment was more similar to DR5 engagement with TRAIL, our results suggest that TRAIL might be able to induce inflammatory cytokine release under certain circumstances. Interestingly, Weckmann et al. [33] reported a link between TRAIL and CCL20, which supports our conclusion.

\section{Materials and Methods}

\section{Cell lines and reagents}

The 293T (human embryonic kidney cells transformed with the $\mathrm{T}$ antigen of SV40), MDA-MB-231 (human breast cancer cells) and HCT-116 (human colon cancer cells) cell lines were provided by American Type Culture Collection (ATCC, Manassas, VA, USA) and maintained in DMEM supplemented with $10 \%$ FCS. IKK inhibitor II (Wedelolactone) was provided by Merck (Darmstadt, Germany). Mouse anti-human DR5 monoclonal antibody AD5-10 (IgG3) was prepared as described by Guo et al. [22]. Mouse IgG3 isotype control and rabbit anti-human FADD and RIP polyclonal antibodies were purchased from Santa Cruz Biotechnology (Santa Cruz, CA, USA). Rabbit anti-human DR4, DR5 and caspase- 8 polyclonal antibodies were purchased from Chemicon (Temecula, CA, USA).

\section{Constructs}

Gene expression constructs of TRAF2 (87-501), IкB (S32A/ S36A) (Dr Hongbing Shu, Wuhan University, China), IKK $\alpha$ (K44M), IKK $\beta$ (K44A), NIK (K429/430A) (Dr Jiandong Li, University of Rochester Medical Center, USA), FADD (80-205) (Dr Andrew Thorburn, University of Colorado Comprehensive Cancer Center, USA) and CrmA (Dr Andreas Strasser, The Walter and Eliza Hall Institute of Medical Research, Australia) were kind gifts from the indicated sources. Human DcR2 was amplified from a cDNA library and cloned into pCMV-Flag as described previously [34]. TRADD (158-312, S296A, L297A, E299A) was generated by point mutagenesis and cloned into pRK5. pWPXL-DR4 and pWPXL-DR5 were constructed by replacing the eGFP fragment with full-length cDNA of DR4 and DR5.

The NF- $\kappa$ B luciferase reporter plasmid was constructed as previously described [22]. The promoter fragments of other luciferase reporter constructs were amplified from genomic DNA and ligated into the pGL3 basic vector (Promega, Madison, WI, USA). The following primers were used: IL8: 5'-GAT TCT GCT CTT ATG CCT CCA C-3', 5'-AGC TTG TGT GCT CTG CTG TCT CT-3'; CCL20: 5'-AAA TCA AGG TGA AGC TGA-3', 5'-TCT TGG TAC AGC ACA TGG-3'; MIP-2: 5'-TCA GCT AAA CAG GCT TGG AAA-3', 5'-GAG GAG GAG AGC TGG CAA-3'; and MIP1 $\beta$ : 5'-CCC TGT ACC CAG CTC AAT CC-3', 5'-GCT GTG TCC TGT GCT GAT ACT G-3'.

\section{Luciferase assay}

After the required treatments, 293T cells $\left(1 \times 10^{5}\right)$ were lysed 
with Passive Lysis Buffer and luciferase activity was measured with the Dual-Luciferase ${ }^{\circledR}$ Reporter Assay System (Promega, Madison, WI, USA), according to the manufacturer's instructions.

\section{Semi-quantitative RT-PCR}

Cells $\left(1 \times 10^{6}\right)$ were lysed and RNA was isolated with Trizol reagent (Invitrogen, Carlsbad, CA, USA). First-strand cDNA was synthesized with $5 \mu \mathrm{g}$ of total RNA using M-MLV reverse transcriptase (Promega, Madison, WI, USA). Subsequently, RT-PCR was performed and GAPDH was used as a control.

\section{Cytokine measurement}

The culture supernatants were collected to measure cytokine production. The concentrations of IL- 8 and TNF- $\alpha$ were determined by $\mathrm{BD}^{\mathrm{TM}} \mathrm{CBA}$ Human Inflammation Kit (BD Biosciences, San Diego, CA, USA), according to the manufacturer's instructions. CCL20 was measured by an ELISA kit purchased from R\&D (Minneapolis, MN, USA).

\section{Generation of lentiviral vectors}

Lentiviral vectors were produced by co-transfection of 293T cells with pMD2.G, psPAX2 and corresponding pWPXL plasmids using calcium phosphate co-precipitation transfection. $72 \mathrm{~h}$ after transfection, the medium was harvested, centrifuged at $4000 \mathrm{rpm}$ for $10 \mathrm{~min}$, and filtered through a 0.45 - $\mu \mathrm{m}$-pore-size filter.

\section{Immunoprecipitation and Western blot analysis}

After being treated with the AD5-10 monoclonal antibody as indicated, the cells $\left(5 \times 10^{7}\right)$ were collected and lysed with lysis buffer for $1 \mathrm{~h}$ on ice, followed by centrifugation at $12000 \mathrm{rpm}$ at $4{ }^{\circ} \mathrm{C}$ for $10 \mathrm{~min}$ to remove the cell debris. The supernatant was precipitated with goat anti-mouse IgG and protein A-coupled Sepharose beads at $4{ }^{\circ} \mathrm{C}$ for $12 \mathrm{~h}$. After being washed extensively with the lysis buffer, the immuno-complexes were subjected to SDS-PAGE (5\% acrylamide for spacer gel and $12 \%$ acrylamide for separation gel) and transferred to a PVDF membrane (Amersham Biosciences, Buckinghamshire, UK). The membrane was probed with specific antibodies and horseradish peroxidase (HRP)-conjugated antibodies, followed by visualization with a chemiluminescence system (ECL, Amersham Biosciences, Buckinghamshire, UK) and exposure to X-ray film.

\section{Statistical analysis}

All data are expressed as the mean from three experiments. Differences between groups were compared using Student's $t$-test. $P$-values were considered to be statistically significant when less than 0.05 .

\section{Acknowledgments}

We thank Drs Hongbing Shu (Wuhan University, China), Jiandong Li (University of Rochester Medical Center, USA), Andrew Thorburn (University of Colorado Comprehensive Cancer Center, USA) and Andreas Strasser (The Walter and Eliza Hall Institute of Medical Research, Australia) for the generous gifts of the constructs. This work was partially supported by the National Natural Science Foundation of China (Grants 30571687 and 30721063) and the State Key Basic Research Program of China (Grant 2007CB507404).

\section{References}

1 Walczak H, Miller RE, Ariail K, et al. Tumoricidal activity of tumor necrosis factor-related apoptosis-inducing ligand in vivo. Nat Med 1999; 5:157-163.

2 Ashkenazi A, Pai RC, Fong S, et al. Safety and antitumor activity of recombinant soluble Apo2 ligand. J Clin Invest 1999; 104:155-162.

3 Pan G, O'Rourke K, Chinnaiyan AM, et al. The receptor for the cytotoxic ligand TRAIL. Science 1997; 276:111-113.

4 Walczak H, Degli-Esposti MA, Johnson RS, et al. TRAILR2: a novel apoptosis-mediating receptor for TRAIL. EMBO $J$ 1997; 16:5386-5397.

5 Chaudhary PM, Eby M, Jasmin A, Bookwalter A, Murray J, Hood L. Death receptor 5, a new member of the TNFR family, and DR4 induce FADD-dependent apoptosis and activate the NF-kappaB pathway. Immunity 1997; 7:821-830.

6 Sprick MR, Weigand MA, Rieser E, et al. FADD/MORT1 and caspase- 8 are recruited to TRAIL receptors 1 and 2 and are essential for apoptosis mediated by TRAIL receptor 2. Immunity 2000; 12:599-609.

7 Kischkel FC, Lawrence DA, Chuntharapai A, Schow P, Kim KJ, Ashkenazi A. Apo2L/TRAIL-dependent recruitment of endogenous FADD and caspase- 8 to death receptors 4 and 5 . Immunity 2000; 12:611-620.

8 Bodmer JL, Holler N, Reynard S, et al. TRAIL receptor-2 signals apoptosis through FADD and caspase-8. Nat Cell Biol 2000; 2:241-243.

9 Anel A, Bosque A, Naval J, et al. Apo2L/TRAIL and immune regulation. Front Biosci 2007; 12:2074-2084.

10 Grosse-Wilde A, Voloshanenko O, Bailey SL, et al. TRAIL-R deficiency in mice enhances lymph node metastasis without affecting primary tumor development. J Clin Invest 2008; 118:100-110.

11 Zerafa N, Westwood JA, Cretney E, et al. Cutting edge: TRAIL deficiency accelerates hematological malignancies. $J$ Immunol 2005; 175:5586-5590.

12 Cretney E, Uldrich AP, Berzins SP, Strasser A, Godfrey DI, Smyth MJ. Normal thymocyte negative selection in TRAILdeficient mice. J Exp Med 2003; 198:491-496.

13 Lamhamedi-Cherradi SE, Zheng SJ, Maguschak KA, Peschon J, Chen YH. Defective thymocyte apoptosis and accelerated autoimmune diseases in TRAIL-/- mice. Nat Immunol 2003; 4:255-260.

14 Janssen EM, Droin NM, Lemmens EE, et al. CD4+ T-cell help controls CD8+ T-cell memory via TRAIL-mediated activation-induced cell death. Nature 2005; 434:88-93.

15 Li JH, Kirkiles-Smith NC, McNiff JM, Pober JS. TRAIL induces apoptosis and inflammatory gene expression in human endothelial cells. J Immunol 2003; 171:1526-1533.

16 Secchiero P, Corallini F, di Iasio MG, Gonelli A, Barbarotto E, Zauli G. TRAIL counteracts the proadhesive activity of inflammatory cytokines in endothelial cells by down-modulating CCL8 and CXCL10 chemokine expression and release. Blood 2005; 105:3413-3419.

17 Secchiero P, Gonelli A, Carnevale E, et al. TRAIL promotes the survival and proliferation of primary human vascular endothelial cells by activating the Akt and ERK pathways. Circulation 2003; 107:2250-2256. 
18 Zauli G, Pandolfi A, Gonelli A, et al. Tumor necrosis factorrelated apoptosis-inducing ligand (TRAIL) sequentially upregulates nitric oxide and prostanoid production in primary human endothelial cells. Circ Res 2003; 92:732-740.

19 Harper N, Farrow SN, Kaptein A, Cohen GM, MacFarlane M. Modulation of tumor necrosis factor apoptosis-inducing ligand- induced NF-kappa B activation by inhibition of apical caspases. J Biol Chem 2001; 276:34743-34752.

20 Varfolomeev E, Maecker H, Sharp D, et al. Molecular determinants of kinase pathway activation by Apo2 ligand/tumor necrosis factor-related apoptosis-inducing ligand. $J$ Biol Chem 2005; 280:40599-40608.

21 Choi C, Kutsch O, Park J, Zhou T, Seol DW, Benveniste EN. Tumor necrosis factor-related apoptosis-inducing ligand induces caspase-dependent interleukin-8 expression and apoptosis in human astroglioma cells. Mol Cell Biol 2002; 22:724736.

22 Guo Y, Chen C, Zheng Y, et al. A novel anti-human DR5 monoclonal antibody with tumoricidal activity induces caspase-dependent and caspase-independent cell death. J Biol Chem 2005; 280:41940-41952.

23 Vandenabeele P, Declercq W, Beyaert R, Fiers W. Two tumour necrosis factor receptors: structure and function. Trends Cell Biol 1995; 5:392-399.

24 Wang CY, Mayo MW, Korneluk RG, Goeddel DV, Baldwin AS Jr. NF-kappaB antiapoptosis: induction of TRAF1 and TRAF2 and c-IAP1 and c-IAP2 to suppress caspase- 8 activation. Science 1998; 281:1680-1683.

25 Zong WX, Edelstein LC, Chen C, Bash J, Gelinas C. The prosurvival Bcl-2 homolog Bfl-1/A1 is a direct transcriptional target of NF-kappaB that blocks TNFalpha-induced apoptosis. Genes Dev 1999; 13:382-387.

26 Wang CY, Guttridge DC, Mayo MW, Baldwin AS Jr. NFkappaB induces expression of the Bcl-2 homologue A1/Bfl-1 to preferentially suppress chemotherapy-induced apoptosis. Mol Cell Biol 1999; 19:5923-5929.

27 Chen C, Edelstein LC, Gelinas C. The Rel/NF-kappaB family directly activates expression of the apoptosis inhibitor Bclx(L). Mol Cell Biol 2000; 20:2687-2695.

28 Mitsiades CS, Treon SP, Mitsiades N, et al. TRAIL/Apo2L ligand selectively induces apoptosis and overcomes drug resistance in multiple myeloma: therapeutic applications. Blood 2001; 98:795-804.

29 Trauzold A, Wermann H, Arlt A, et al. CD95 and TRAIL receptor-mediated activation of protein kinase $C$ and NF-kap$\mathrm{paB}$ contributes to apoptosis resistance in ductal pancreatic adenocarcinoma cells. Oncogene 2001; 20:4258-4269.

30 Oya M, Ohtsubo M, Takayanagi A, Tachibana M, Shimizu N, Murai M. Constitutive activation of nuclear factor-kappaB prevents TRAIL-induced apoptosis in renal cancer cells. Oncogene 2001; 20:3888-3896.

31 Wuchter C, Krappmann D, Cai Z, et al. In vitro susceptibility to TRAIL-induced apoptosis of acute leukemia cells in the context of TRAIL receptor gene expression and constitutive NF-kappa B activity. Leukemia 2001; 15:921-928.

32 Kurbanov BM, Fecker LF, Geilen CC, Sterry W, Eberle J. Resistance of melanoma cells to TRAIL does not result from upregulation of antiapoptotic proteins by NF-kappaB but is related to downregulation of initiator caspases and DR4. Oncogene 2007; 26:3364-3377.

33 Weckmann M, Collison A, Simpson JL, et al. Critical link between TRAIL and CCL2 0 for the activation of T(H)2 cells and the expression of allergic airway disease. Nat Med 2007; 13:1308-1315.

34 Pan G, Ni J, Yu G, Wei YF, Dixit VM. TRUNDD, a new member of the TRAIL receptor family that antagonizes TRAIL signaling. FEBS Lett 1998; 424:41-45. 